\title{
Synchrotron-based X-ray tomographic microscopy for rock physics investigations
}

\author{
Claudio Madonna ${ }^{1}$, Beatriz Quintal ${ }^{1}$, Marcel Frehner ${ }^{1}$, Bjarne S. G. Almqvist ${ }^{1}$, Nicola Tisato ${ }^{1}$, \\ Mattia Pistone ${ }^{1}$, Federica Marone ${ }^{2}$, and Erik H. Saenger ${ }^{1}$
}

\begin{abstract}
Synchrotron radiation $\mathrm{X}$-ray tomographic microscopy is a nondestructive method providing ultra-high-resolution 3D digital images of rock microstructures. We describe this method and, to demonstrate its wide applicability, we present 3D images of very different rock types: Berea sandstone, Fontainebleau sandstone, dolomite, calcitic dolomite, and three-phase magmatic glasses. For some samples, full and partial saturation scenarios are considered using oil, water, and air. The rock images precisely reveal the 3D rock microstructure, the pore space morphology, and the interfaces between fluids saturating the same pore. We provide the raw image data sets as online supplementary material, along with laboratory data describing the rock properties. By making these data sets available to other research groups, we aim to stimulate work based on digital rock images of high quality and high resolution. We also discuss and suggest possible applications and research directions that can be pursued on the basis of our data.
\end{abstract}

\section{INTRODUCTION}

Three-dimensional information of rock microstructures is important for better understanding physical phenomena taking place at that scale (e.g., Sakellariou et al., 2007; Degruyter et al., 2010; Bai et al., 2011; Saenger et al., 2011; Pistone et al., 2012) and for rock characterization (e.g., Arns et al., 2001a; Dvorkin et al., 2008; Knackstedt et al., 2009; Madonna et al., 2012). Various methods for obtaining a 3D image of the rock microstructure exist. They can be separated into two major groups: destructive and nondestructive methods. If possible, the latter is preferable because the same rock sample can be used for further investigations after imaging, for example in laboratory testing. This allows a direct comparison between laboratory tests and calculations based on a digital rock image. The most common nondestructive 3D imaging method for earth sciences is X-ray computed tomography (CT). Figure 1 compares different resolutions and possible sample sizes for different types of X-ray CT methods. There is a clear trade-off between sample size and resolution. For each single material sample, the question has to be clarified if the chosen sample size is representative for the given task to be considered. In the last decade, the X-ray microcomputed tomography (micro-CT) method became widely available and many modern studies have made use of it to obtain $3 \mathrm{D}$ rock images. The resolution of micro-CT (Figure 1) is high enough to image the spatial distribution of grains, pores, and pore fluids. The resulting 3D digital rock images are often used in numerical models to simulate various physical processes on the porescale. We give here two examples: First, Zhu et al. (2007) developed a digital-image-based simulation methodology, which is applied to evaluate the influence of heterogeneities in the porosity distribution on the evolution of tracer concentrations in imaged tracer tests. Second, Saenger et al. (2011) used a 3D rock image to numerically simulate the signature of a theoretically predicted slow S-wave, which is an effect of a viscous pore fluid.

Additionally, 3D rock images can be used for predicting properties such as porosity, permeability, pore size distribution, effective elastic moduli, and electrical conductivity. For example, permeability can be successfully predicted by numerically simulating fluid flow through 3D rock models, with the numerical results being in reasonable agreement with laboratory measurements (Arns et al., 2004; Fredrich, et al., 2006; Dvorkin et al., 2008; Degruyter et al., 2010; Narváez et al., 2010). In this case, the resolution of the microCT technique is sufficient because fluid pathways predominantly follow larger pores. However, if the porosity is much smaller than $1 \mu \mathrm{m}$ (e.g., shale) the agreement might be less satisfactory because

\footnotetext{
Manuscript received by the Editor 30 March 2012; revised manuscript received 17 August 2012; published online 18 January 2013.

${ }^{1}$ ETH Zurich, Department of Earth Sciences, Zurich, Switzerland. E-mail: claudio.madonna@erdw.ethz.ch; beatriz.quintal@erdw.ethz.ch; marcel.frehner@ erdw.ethz.ch; bjarne.almqvist@erdw.ethz.ch; nicola.tisato@erdw.ethz.ch; mattia.pistone@erdw.ethz.ch; erik.saenger@erdw.ethz.ch.

${ }^{2}$ Paul Scherrer Institute, Swiss Light Source, Villigen, Switzerland. E-mail: federica.marone@psi.ch.

(C) 2013 Society of Exploration Geophysicists. All rights reserved.
} 
of resolution limitations. On the other hand, mechanical properties, such as the effective elastic moduli, strongly depend on the microstructural details of the rock (e.g., Kuster and Toksöz, 1974; O'Connell and Budiansky, 1974), which are unresolved by the micro-CT technique. The inability to fully characterize the microstructural details of a rock can lead to disagreements between numerical estimates of mechanical properties based on micro-CT images and laboratory data. However, Madonna et al. (2012) recently described a method to successfully resolve this problem for relatively homogeneous rocks. They use a grain-contact reconstruction technique for segmenting the micro-CT images and, subsequently, calibrate the numerical simulations with laboratory measurements. The results provide an understanding of the effect of the rock microstructure on the P-wave velocity. Another method, suggested by Dvorkin et al. (2011), consists of comparing trends formed by data points from computational and laboratory measurements, instead of direct point-to-point comparisons. Similar disagreement between laboratory data and computationally calculated data based on tomographic images has been observed and treated for electric conductivity (e.g., Arns, 2011).

The limitations of traditional X-ray micro-CT instruments in fully characterizing the microstructural details of rocks can be significantly reduced by using third-generation synchrotron sources, thanks to their exceptional photon density. The high brilliance of third-generation synchrotron radiation provides increased spatial and temporal resolution. Brilliance (i.e., light intensity) is defined as the number of photons per second per unit source area, emitted per solid angle within a certain wavelength band. The detection of details as small as 1 micron in millimeter-sized samples is routinely possible within only a few minutes. In addition, the monochromaticity of the X-ray beam allows for quantitative measurements of material properties (e.g., density) and simplifies the identification of the different X-rayed phases, because beam hardening artifacts (Barrett and Keat, 2004), distinctive for micro-CT setups, can be avoided. Increased contrast and reduced noise are also promoted by the monochromatic beam and the high photon flux. All of these

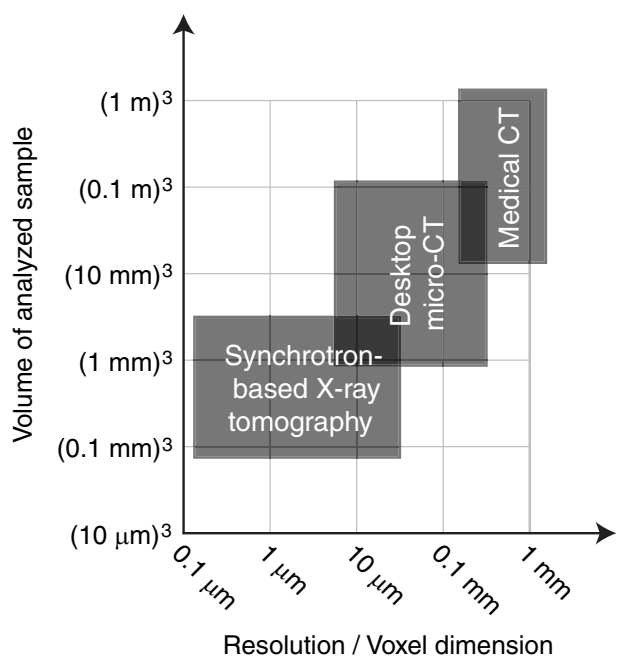

Figure 1. Schematic representation of sample size versus resolution of the most common X-ray computed tomography methods. Other methods are available, but are not plotted here; for example laboratory-sized micro-CT, which has a similar resolution as SRXTM, but much lower brilliance leading to lower data quality. factors result in high-resolution images of astonishing quality, which allow a much more detailed analysis compared to microCT images.

For this paper, we have employed synchrotron radiation X-ray tomographic microscopy (SRXTM) to obtain high-resolution 3D images of samples of:

- Dry and water-saturated Fontainebleau sandstone.

- Dry and partially saturated (with two or three fluid phases) Berea sandstone.

- Dry dolomite and calcitic dolomite.

- Three-phase magmatic glass and high-temperature vesiculating magma.

We chose such a wide range of different rock samples to demonstrate the power and versatility of the SRXTM-method. On one hand, we deliver images of two standard rocks, Berea and Fontainebleau sandstones, which are often considered as analogs for siliciclastic reservoirs and are therefore intensively studied and characterized. On the other hand, imaging magmatic glass and magma demonstrates the wide applicability of the method also to nonporous materials. The SRXTM-methodology and the resulting images are described and shown in the following sections. We provide the raw data of all the images as supplementary files as an incentive to the development of rock physics research using high-resolution digital rock images, which have been of scarce access to a broad scientific community.

\section{METHODOLOGY}

SRXTM is a powerful technique for fast, nondestructive, highresolution, quantitative volumetric investigations on diverse samples. Our data sets were acquired at the TOMCAT (TOmographic Microscopy and Coherent rAdiology experimenTs; Stampanoni et al., 2006) beam-line at the Swiss Light Source (SLS; Paul Scherrer Institute, Villigen, Switzerland). For all case studies (see below case 1-9), except for case 9, for which the aim was high photon flux and therefore acquisition speed, the monochromatic beam energy was optimized for best contrast. Transmitted X-rays were converted into visible light by a 20 micron Ce-doped LAG (Lutetium Aluminum Garnet) scintillator screen (Crytur, Czech Republic). Projections were magnified by microscope optics and digitized by a high-resolution CCD camera (PCO.2000, PCO AG, Germany), which results in 8- or 16-bit tif-format images. One complete data set can be acquired within a few minutes. Detailed experimental parameters are given in Table 1. Tomographic volumes were reconstructed using a highly optimized algorithm based on Fourier methods (Marone et al., 2010). Our samples consisted of $2 \mathrm{~mm}$ diameter cylindrical cores drilled from the starting rocks. The height of the samples ranged from 2 to $4 \mathrm{~mm}$. Cylinders represent the best geometry to capture maximum volume (Ketcham and Carlson, 2001), avoiding artifacts due to insufficient spatial sampling. Specimens were mounted on brass holders and fixed with wax.

For case study 9 (magma foaming) a newly commissioned ultrafast end-station (Mokso et al., 2010), equipped with a laser-based heating system (Fife et al., 2012), best suited for in situ dynamic experiments, was employed. If polychromatic $\mathrm{X}$-ray radiation (white beam) is used, the photon flux is high enough to acquire complete high-resolution (1-3 microns pixel size) tomographic data sets in less than $1 \mathrm{~s}$, enabling investigations of dynamic processes in $3 \mathrm{D}$ without motion artifacts. To achieve this acquisition speed, a 
camera based on CMOS technology is essential. Because for this type of camera each single pixel is equipped with readout electronics, the readout time becomes negligible, enabling the acquisition of more than 1000 fps. As a comparison, standard CCD camera chips usually have a maximum of four readout nodes, with dead-times of several hundred milliseconds. For case study 9, a cylindrical sample core ( $2 \mathrm{~mm}$ in diameter; $2 \mathrm{~mm}$ in height) was inserted into an X-ray transparent boron nitride holder and placed inside the novel laser-based heating system (Fife et al., 2012).

\section{CASE STUDIES}

The presented rock images exploit the absorption contrast of the synchrotron beam in gray values. The brighter the gray value is, the higher the absorption of the beam was. To a first order, the absorption is proportional to the material density. Therefore, for example, ankerite appears brighter in the images compared to air. Sometimes, the single phases can be easily detected by eye when scrolling through neighboring slices. For a quantitative analysis, each phase of interest has to be identified in the data. This is normally done by attributing a certain range of gray color to a particular phase and is called segmentation. The process of segmentation itself is a subject of current research and is discussed, for example, by Gao and Wong (1989). Here, our objective is only to provide and explain the raw data sets ${ }^{3}$, therefore we do not address in detail segmentation techniques and only show segmented images as examples in few case studies. Different algorithms already implemented in several 3D analysis software packages are available for image segmentation. For example, Image $\mathbf{J}$ is free to download, or several Matlab scripts are available from the Mathworks Web page. Moreover, advanced 3D analysis software (e.g., Avizo, VSG, France) can be used to segment the images with different techniques.

Due to the experimental setup at the TOMCAT beam line, the data in an inner volume of the data cube will provide highest quality. This region is marked as a white dashed circle in the figures showing raw data (Figures 2a, 3, 6, 7, 8, 9, 10, 11, 13, and 15a). The corners contain artifacts due to less complete data related to the rotation symmetry inherent in tomography. For an accurate analysis, we suggest to preferably use the data within the marked region.

\section{Case 1: Fontainebleau sandstone}

A dry sample of Fontainebleau sandstone was imaged (Figure 2) with the experimental conditions given in Table 1. Fontainebleau sandstone is often referred to as an analog rock for siliciclastic hydrocarbon reservoirs and has already been investigated in other digital rock studies (e.g., Arns et al., 2002). Fontainebleau sandstone is homogeneous and is almost entirely composed of quartz grains. Despite some possible impurities, this should be a relatively simple system and laboratory rock characterization data are available over a broad range of porosities (e.g., Han, 1986). To determine porosity, helium density porosimetry experiments were performed on a $25.4 \mathrm{~mm}$ diameter, $37.5 \mathrm{~mm}$ length sample using a Helium Pycnometer 1330 (Micrometrics Instrument Corp., Belgium). The average porosity of our sample is $5.1 \mathrm{vol} \%$.

A single 2D SRXTM-slice of Fontainebleau sandstone (Figure 2a) shows quartz grains with sharp edges, and the pore connectivity seems to be low. However, the 3D view of the pore space (Figure 2b) reveals a high connectivity of the pores. This demonstrates the importance of $3 \mathrm{D}$ imaging techniques for investigating the rock microstructure. To visualize the pore volume in Figure $2 b$, we segmented the data using the software Avizo (VSG, France). To identify the two phases, grains and pores, threshold segmentation was applied to the raw data by manually choosing the gray level windows for the different phases. Additionally, we applied the edge-preserving smoothing algorithm provided by Avizo. Because the Fontainebleau sandstone consists mainly of quartz, and the images are of high quality, no further filter was needed.

Because the quartz grains in the Fontainebleau sandstone contain very sharp edges, this data set exhibits so-called exponential edgegradient effects (Joseph and Spital, 1981). These effects manifest themselves as bright straight lines originating from the grain edges (Figure 2a).

\section{Case 2: Water-saturated Fontainebleau sandstone}

The second image of Fontainebleau sandstone (Figure 3) is from the same rock sample as the first image. The specific $2 \mathrm{~mm}$ diameter specimen was saturated through imbibition (e.g., Dullien, 1992). First, a few ml volume vial had been filled with water. Second,

Table 1. Experimental conditions and characteristics of the raw data.

\begin{tabular}{|c|c|c|c|c|c|c|}
\hline Case & Beam energy & Exposure time & Size of data cube & Magnification & Voxel size & Pixel depth \\
\hline 1 & $26 \mathrm{keV}$ & $500 \mathrm{~ms}$ & $1024 \times 1024 \times 1024$ & $10 \times$ & $(0.74 \mu \mathrm{m})^{3}$ & 16 bit \\
\hline 2 & $26 \mathrm{keV}$ & $300 \mathrm{~ms}$ & $1024 \times 1024 \times 1024$ & $20 \times$ & $(0.38 \mu \mathrm{m})^{3}$ & 16 bit \\
\hline 3 & $26 \mathrm{keV}$ & $500 \mathrm{~ms}$ & $1024 \times 1024 \times 1024$ & $10 \times$ & $(0.74 \mu \mathrm{m})^{3}$ & 16 bit \\
\hline 4 & $26 \mathrm{keV}$ & $300 \mathrm{~ms}$ & $1024 \times 1024 \times 1024$ & $20 \times$ & $(0.38 \mu \mathrm{m})^{3}$ & 16 bit \\
\hline 5 & $26 \mathrm{keV}$ & $500 \mathrm{~ms}$ & $1024 \times 1024 \times 1024$ & $10 \times$ & $(0.74 \mu \mathrm{m})^{3}$ & 16 bit \\
\hline 6 & $22.6 \mathrm{keV}$ & $300 \mathrm{~ms}$ & $2048 \times 2048 \times 2048$ & $20 \times$ & $(0.38 \mu \mathrm{m})^{3}$ & 8 and 16 bit \\
\hline 7 & $22.6 \mathrm{keV}$ & $300 \mathrm{~ms}$ & $2048 \times 2048 \times 2048$ & $20 \times$ & $(0.38 \mu \mathrm{m})^{3}$ & 8 and 16 bit \\
\hline 8 & $20 \mathrm{keV}$ & $100 \mathrm{~ms}$ & $2048 \times 2048 \times 2048$ & $10 \times$ & $(0.74 \mu \mathrm{m})^{3}$ & 16 bit \\
\hline 9 & Polychromatic & $1.4 \mathrm{~ms}$ & $1008 \times 1008 \times 2016$ & $\sim 3.7 \times$ & $(2.96 \mu \mathrm{m})^{3}$ & 8 bit \\
\hline
\end{tabular}

${ }^{3}$ At the time of publication, data are available for downloading from www.rockphysics.ethz.ch/downloads. 
the specimen was inserted into the vial and submerged in the liquid. Third, the vial was kept in a vacuum chamber at $~ 50$ mbar for a few hours. Due to the small sample size and the relatively high porosity, we reached nearly $100 \%$ saturation of the connected pores with this procedure. However, air is still partially present in the pore space. Because here a higher resolution is chosen compared to case 1 (see Table 1), the nonconnected porosity is well-resolved (small dots in Figure 3 ). As in case 1, the exponential edge-gradient effects are also present here.

a)

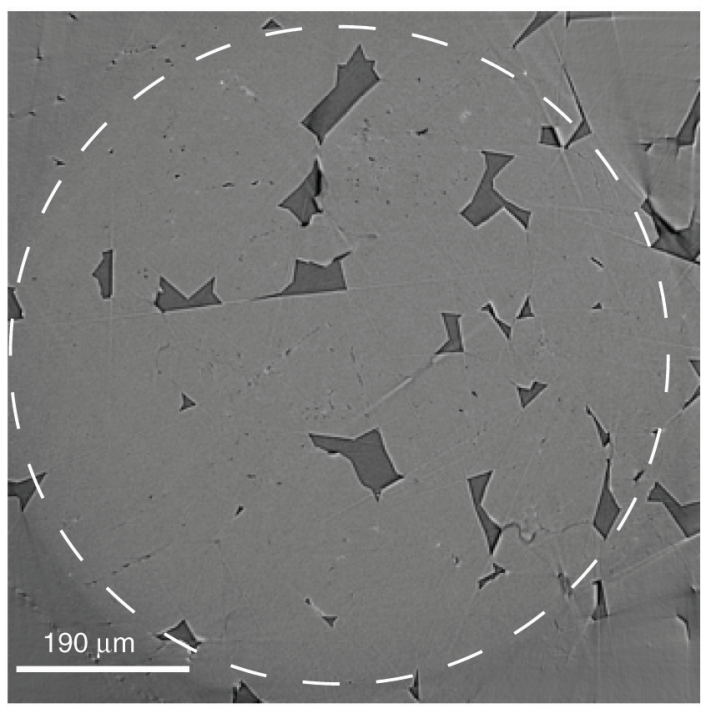

b)

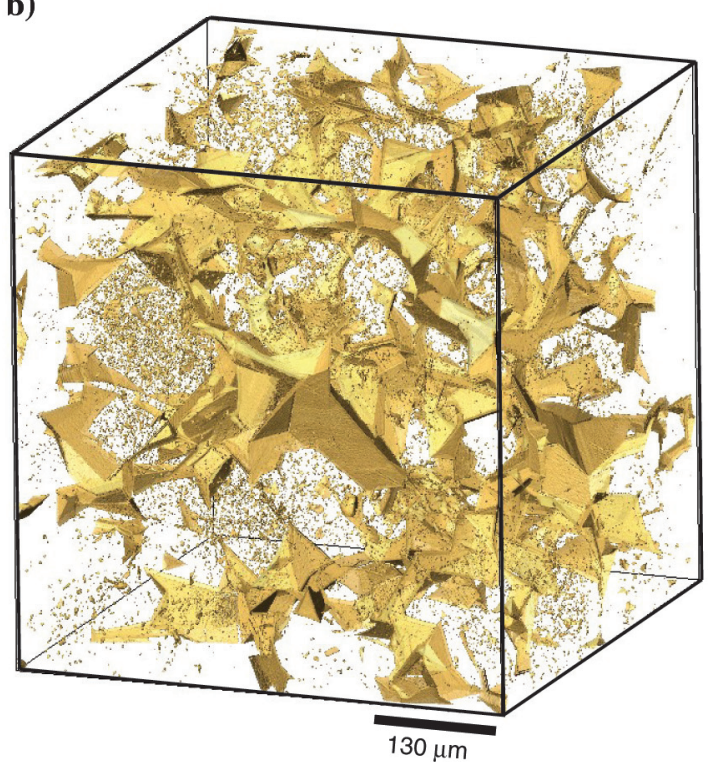

Figure 2. (a) Axial slice through the SRXTM-volume of dry Fontainebleau sandstone. Dark gray areas are empty pores; light gray areas are quartz grains. The corresponding file name of this slice of the full data set provided with $1024^{3}$ voxels is ' $\mathrm{F} 2$ - 10 0001.rec.16bit.tif'. The voxel size is $(0.74 \mu \mathrm{m})^{3}$. Due to the experimental setup, the maximum data quality is only within the marked dashed circle. (b) 3D visualization of the SRXTM-volume of dry Fontainebleau sandstone. Only the pore space is shown in yellow; the quartz grains are not shown.

\section{Case 3: Dry Berea sandstone}

For the imaging and laboratory experiments of Berea sandstone, a sample from the Berea Sandstone ${ }^{\mathrm{TM}}$ Petroleum Cores (Ohio, USA) was used. Berea sandstone is frequently used as analog rock for siliciclastic hydrocarbon reservoirs and, therefore, is wellstudied and characterized. To determine porosity, helium density and mercury porosimetry were performed on a $25.4 \mathrm{~mm}$ diameter, $37 \mathrm{~mm}$ length sample using a Helium Pycnometer 1330 (Micromeritics Instrument Corp., Belgium) and a Pascal $140+440$ Mercury Porosimeter (Thermo Electron Corporation, Germany), respectively. Mercury porosimetry measurements were performed as described by Giesche (2006). The result is shown in Figure 4. The connected porosity is around $20 \%$. Permeability as provided by the company Berea Sandstone ${ }^{\mathrm{TM}}$ Petroleum Cores is between 200 and

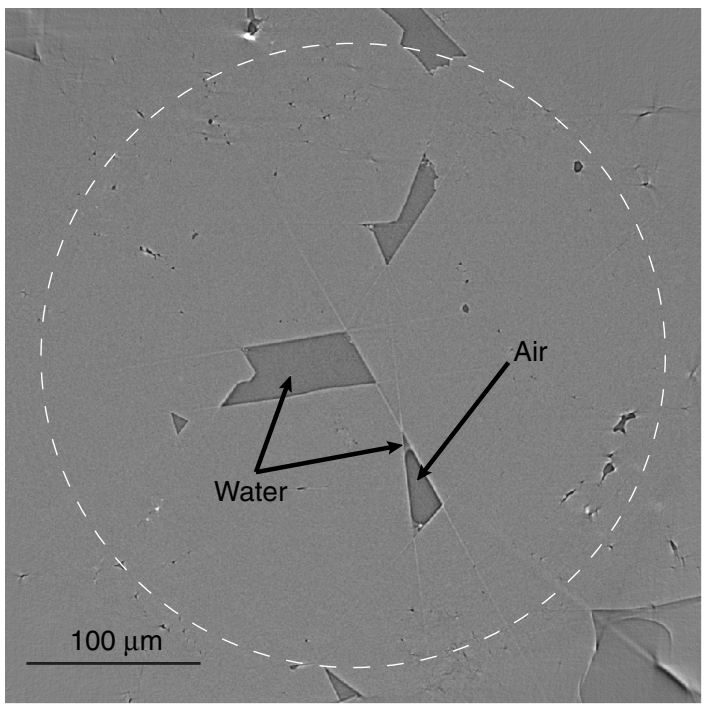

Figure 3. Raw SRXTM-image of water-saturated Fontainebleau sandstone. One slice (F1r_0001.rec.16bit.tif) of the total data cube with $1024^{3}$ voxels and a voxel size of $(0.38 \mu \mathrm{m})^{3}$ (Table 1$)$ is shown. The full data cube is available with this publication.

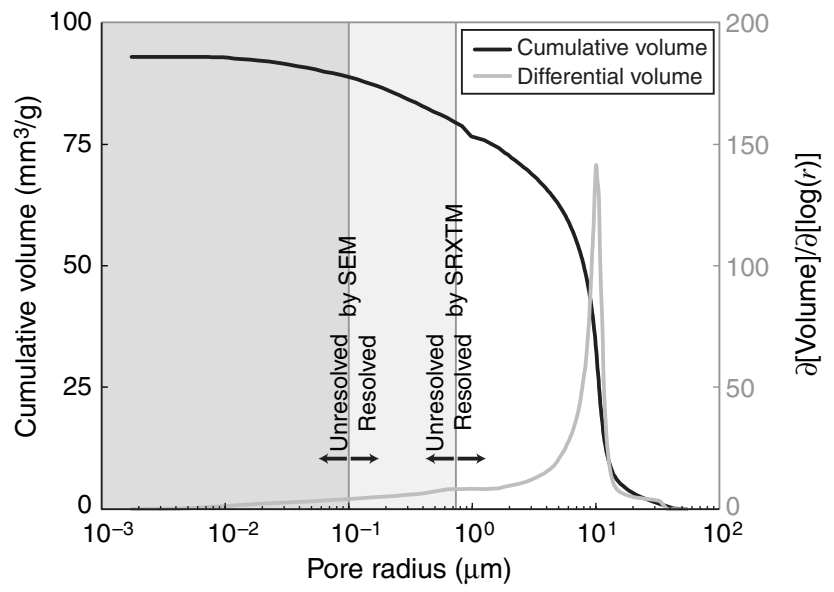

Figure 4. Pore size distribution of the Berea sandstone sample, which was determined by mercury intrusion porosimetry. 
$500 \mathrm{mD}$. The mineral composition has been confirmed with petrographic microscopy and electron microprobe (Figure 5). The results of a mineral texture analysis (Madonna et al., 2012) show that for the analyzed Berea sandstone the predicted elastic tensor of the solid can be considered isotropic, with calculated velocity anisotropy of less than $1 \%$. The ultrasonic P-wave velocities were also measured by Madonna et al. (2012) on a $25.4 \mathrm{~mm}$ diameter, $40 \mathrm{~mm}$ length sample over a range of confining pressures from 5 to $230 \mathrm{MPa}$ by applying the pulse transmission technique (Birch, 1960; Christensen, 1965; Toksöz et al., 1979; Ferri et al., 2007) at $3 \mathrm{MHz}$. They vary from $2300 \mathrm{~m} / \mathrm{s}$ at $5 \mathrm{MPa}$ to $4000 \mathrm{~m} / \mathrm{s}$ at $230 \mathrm{MPa}$. Figure 6 shows an axial slice through the SRXTMvolume of dry Berea sandstone.

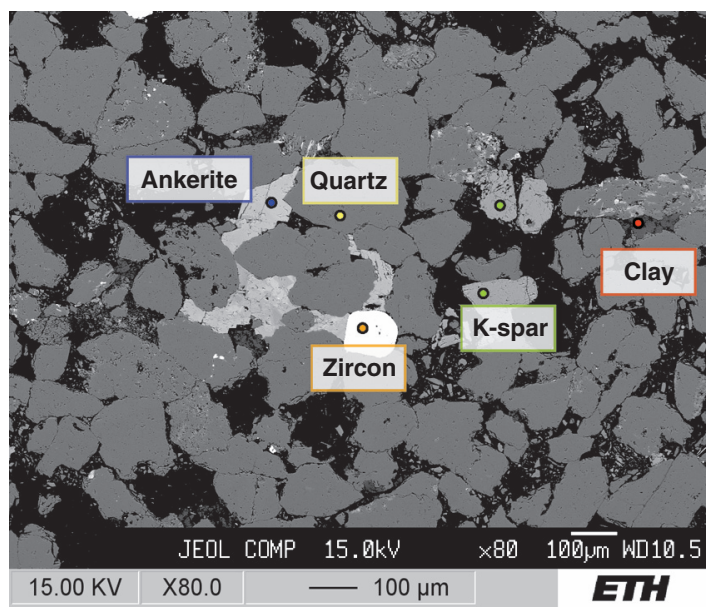

Figure 5. Backscattered electron microscopy (BSE) image of a Berea sandstone sample with the mineral phases identified.

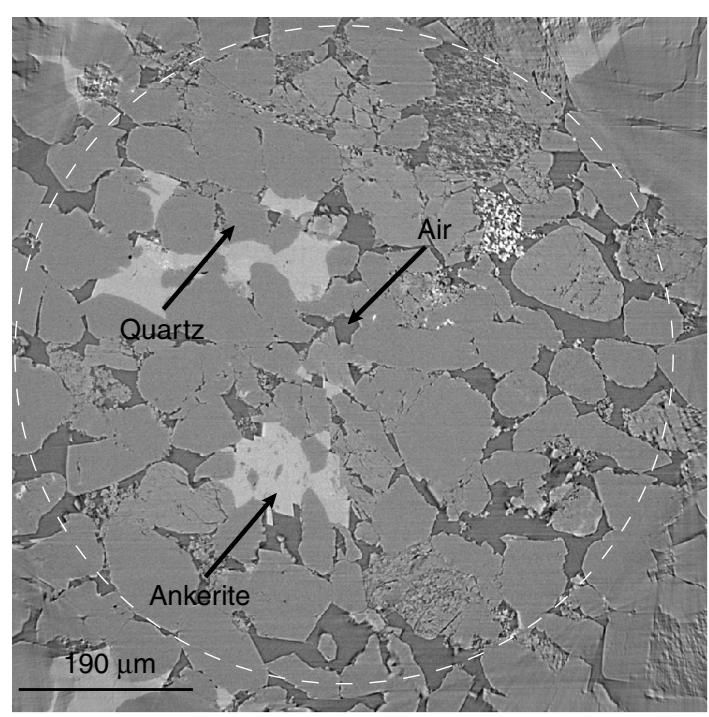

Figure 6. Raw SRXTM-image of dry Berea sandstone. One slice (B14_0001.rec.16bit.tif) of the total data cube with $1024^{3}$ voxels and a voxel size of $(0.74 \mu \mathrm{m})^{3}$ (see Table 1$)$ is shown.

\section{Case 4: Different saturation scenarios of Berea sandstone}

In this experiment, another specimen of Berea sandstone from the same block is imaged for three subsequent saturation scenarios. With the same imbibition technique as described in case 2, we saturated the Berea sandstone sample with Angiofil oil (viscosity = $3.4 \mathrm{mPa}$ s at $20^{\circ} \mathrm{C}$; Grabherr et al., 2008). The SRXTM-image of the nearly fully oil-saturated sample is shown in Figure 7.

After the first scan of the almost fully oil-saturated Berea sandstone, our aim was to create partially saturated stages with the same specimen. A four-step technique was employed:

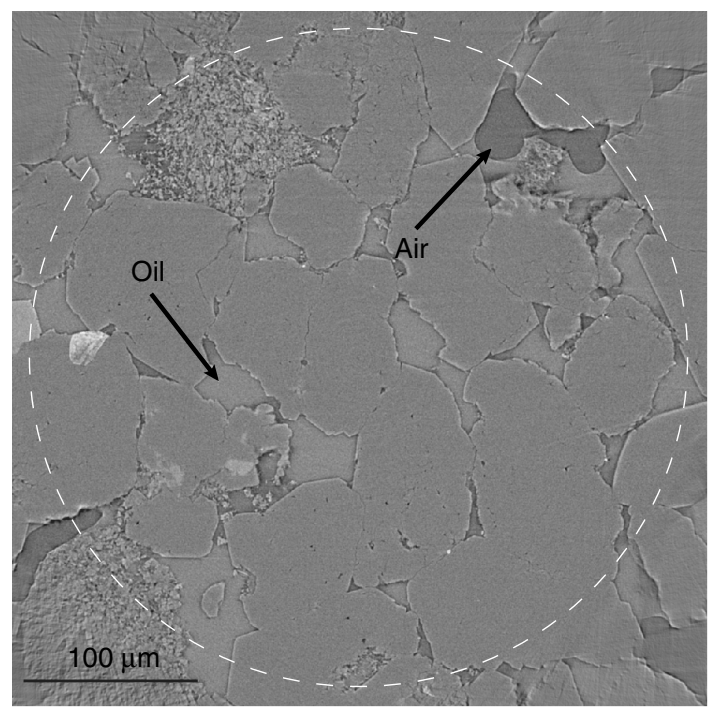

Figure 7. Raw SRXTM-image of oil-saturated Berea sandstone. One slice (B4_0001.rec.16bit.tif) of the total data cube with $1024^{3}$ voxels and a voxel size of $(0.38 \mu \mathrm{m})^{3}$ (Table 1$)$ is shown.

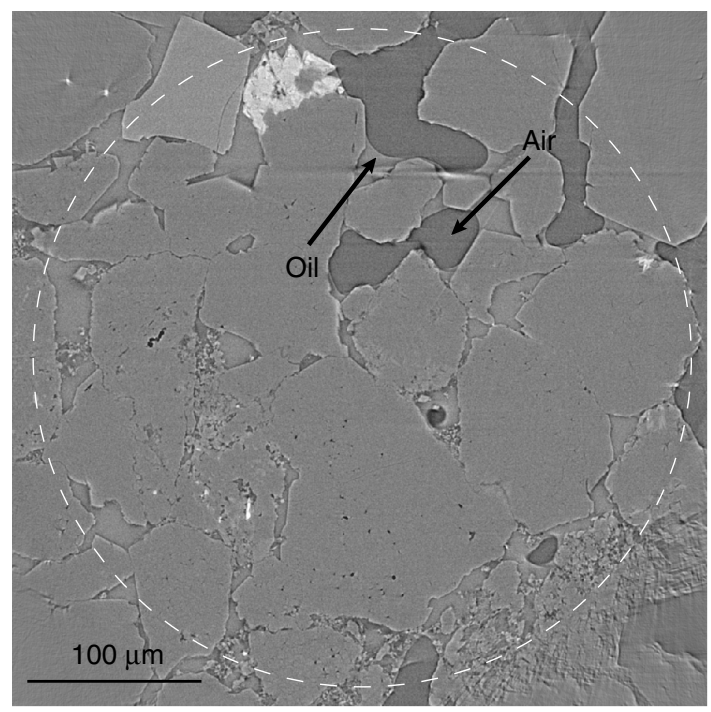

Figure 8. Raw SRXTM-image of Berea sandstone partially saturated with air and oil. One slice (B4_2_0001.rec.16bit.tif) of the total data cube with $1024^{3}$ voxels with and a voxel size of $(0.38 \mu \mathrm{m})^{3}$ (Table 1) is shown. 


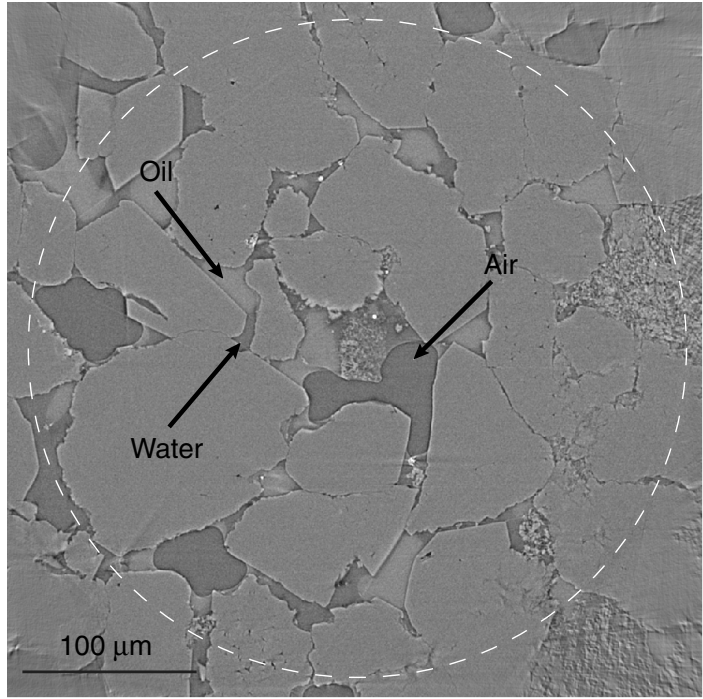

Figure 9. Raw SRXTM-image of Berea sandstone partially saturated with water, air, and oil. One slice (B4_3_0001.rec.16bit.tif) of the total data cube with $1024^{3}$ voxels and a voxel size of $(0.38 \mu \mathrm{m})^{3}$ (Table 1$)$ is shown.

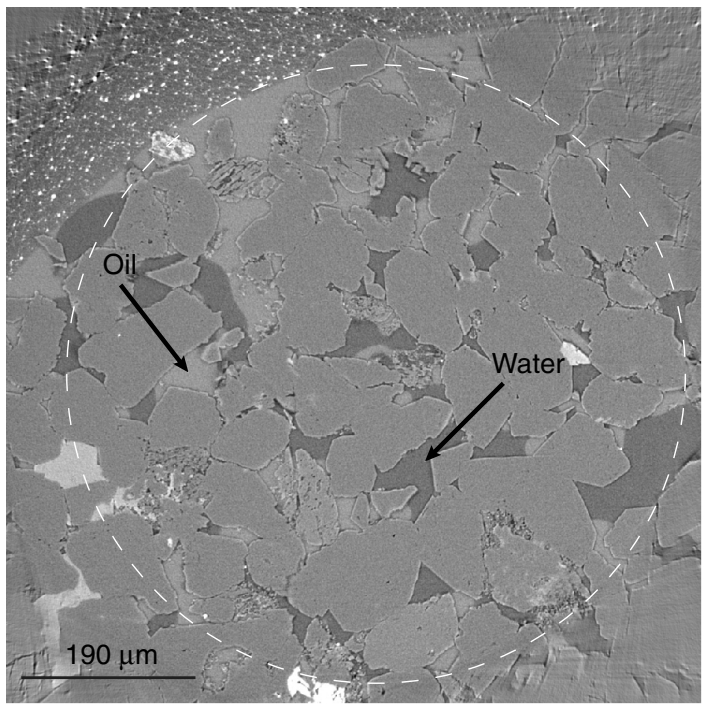

Figure 10. Raw SRXTM-image of Berea sandstone partially saturated with water and oil. One slice (B10_10_A_W_0001.rec.16bit.tif) of the total data cube with $1024^{3}$ voxels and a voxel size of $(0.74 \mu \mathrm{m})^{3}$ (Table 1) is shown.
1) The specimen was enveloped in a $\sim 2 \mathrm{~mm}$ inner diameter polyolefin shrink tube.

2) The specimen, surrounded by the shrink tube, was placed inside one end of a $3 \mathrm{~mm}$ inner diameter, $\sim 10 \mathrm{~cm}$ long latex pipe.

3) The other end of the pipe was connected to a $10 \mathrm{ml}$ syringe filled with the new liquid.

4) Finally, acting on the syringe piston, a flux of liquid was forced to flow through the specimen.

This technique was subsequently applied twice to our specimen. First, we injected air, which pushed the oil out of the pore space. As a result, two phases, air and oil, occupied the connected pores (Figure 8). Second, we injected water. Hence, three phases were expected in the pore space; water, air, and oil (Figure 9).

\section{Case 5: Another saturation scenario of Berea sandstone}

Using a small vacuum pump, a dry sample of Berea sandstone was first saturated with the same Angiofil oil as in case 4, and subsequently with water, which leads to a partial saturation of oil and water. This procedure completes the different saturation scenarios described in the previous case. In contrast to case 4, we have the two saturating phases, oil and water, and a lower magnification. Therefore, more grains are visible in the image shown in Figure 10.

\section{Case 6: Trigodonusdolomit, Upper Muschelkalk (northern Switzerland)}

Cases 6 and 7 provide image data sets for two dry carbonate rock specimens that originate from a core drilled in northern Switzerland (NAGRA, 2001). As part of the laboratory investigation density, porosity, ultrasonic $\mathrm{P}$ - and $\mathrm{S}$-wave velocities, and the permeability were measured. The cores used for laboratory measurements had a diameter of $25.4 \mathrm{~mm}$ and lengths of $35.56 \mathrm{~mm}$ (BEN825.0-3a, case 6) and $29.92 \mathrm{~mm}$ (BEN864.1-b, case 7), respectively. The ultrasonic wave speeds were measured at room temperature and pressure conditions. Permeability measurements were made using the transient step technique (Brace et al., 1968), with a confining pressure of $9 \pm 0.1 \mathrm{MPa}$ and a pore pressure of $1.5 \pm 0.1 \mathrm{MPa}$ for specimen 825.0-3a and 2.1 $\pm 0.1 \mathrm{MPa}$ for specimen BEN864.1-b, respectively. In both experiments, the differential pressure between the two pore pressure reservoirs was $0.5 \mathrm{MPa}$. Permeability measurements were performed at room temperature. A summary of these properties for both specimens is given in Table 2. In general, carbonate rocks are heterogeneous. Therefore, a comparison of laboratory measurements performed on $\mathrm{cm}$-scale specimens and image analysis on $\mu \mathrm{m}$-scale specimens is not straightforward. Nevertheless, the laboratory measurements provide complimentary information to the image analysis, especially when considering physical properties at different scales.

Table 2. Rock properties for cases 6 and 7.

\begin{tabular}{|c|c|c|c|c|c|c|}
\hline Specimen & Composition & Density $\left(\mathrm{kg} / \mathrm{m}^{3}\right)$ & Porosity (\%) & Permeability (mD) & $\operatorname{Avg} V_{\mathrm{P}}(\mathrm{km} / \mathrm{s})$ & $\operatorname{Avg} V_{\mathrm{S}}(\mathrm{km} / \mathrm{s})$ \\
\hline BEN825.0-3a & Dolomite & $2370 \pm 90$ & $17.0 \pm 4.0$ & $1.47-2.48$ & $3.99 \pm 0.34$ & $2.45 \pm 0.16$ \\
\hline
\end{tabular}


The first specimen (BEN825.0-3a, representing case 6) was recovered at $825 \mathrm{~m}$ depth below surface (d.b.s.), in the upper part of the Muschelkalk Formation (Trigodonusdolomit unit). It is almost completely dolomitized with 95 to 100 vol\% dolomite (NAGRA, 2001). In parts of the image sequence (indicated also in Figure 11), there is a cluster of Kaolinite crystals present. The original sediments indicate a carbonate platform depositional environment with intermittent high-energy storm events (Aigner, 1985). Dolomitization processes subsequently produced characteristic macropores (drusy porosity) with pore sizes up to several centimeters. These macropores resulted from the dissolution of anhydrite nodules and calcareous fossils and typically occurred in intermittent, 5-10 cm-thick layers throughout the Trigodonusdolomit unit. Denser layers with a lower concentration of macropores separate the macroporous layers. In addition, dolomitization had a strong influence on micropore $(<1 \mathrm{~mm})$ development. Micropores are commonly heterogeneously distributed as interstitial voids between rhombohedral dolomite crystals (Figure 11). Micropore sizes range broadly between $10 \mathrm{~nm}$ to $10 \mu \mathrm{m}$, as inferred from mercury porosimetry and the SRXTM-images (Figure 12a). Some minor exponential edge-gradient effects also occur in this image data set.

\section{Case 7: Hauptmuschelkalk, Upper Muschelkalk (northern Switzerland)}

The second image data set (specimen BEN864.1-b) was recovered from the Hauptmuschelkalk (Upper Muschelkalk), $864 \mathrm{~m}$ d.b.s. (Figure 13). It comprises a mixture of dolomite ( $\sim 70 \mathrm{vol} \%)$, calcite ( 20 vol\%), minor amounts of clay minerals ( $\sim 5$ vol\%), and quartz and feldspar (1-2 vol\%; NAGRA, 2001). Micropores are generally small $(<100 \mu \mathrm{m})$ and heterogeneously distributed. In contrast to the Trigodonusdolomit, the Hauptmuschelkalk has a more uniform size-distribution of micropores, with a dominant peak between 10 and $100 \mathrm{~nm}$ (Figure 12b), which is well below the resolution of the SRXTM-images. Therefore, it is not possible to directly determine from these images whether the

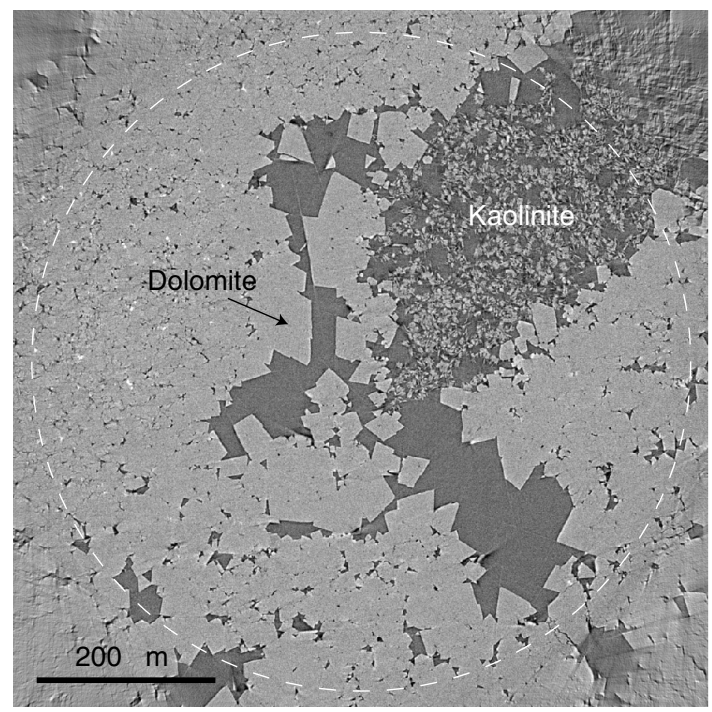

Figure 11. A single raw SRXTM-image (8253a1222) of specimen BEN825.0-3a comprising an area of $2048 \times 2048$ pixels (voxel size is $\left.(0.38 \mu \mathrm{m})^{3}\right)$. The total data cube includes a stack of 2048 images (Table 1). microporosity is intracrystalline, intercrystalline, or both. However, intracrystalline microporosity slightly modifies the effective grain density, and therefore the X-ray absorption and gray level of the respective grains (Vanorio and Mavko, 2011). This effect is very difficult to detect in Figure 13 because the gray level contrast between dolomite and calcite is much stronger. To distinguish intracrystalline from intercrystalline microporosity, other imaging methods, such as BSE (e.g., Figure 5), have to be applied.

\section{Case 8: Three-phase magmatic glass}

A synthetic three-phase hydrous haplogranitic magmatic glass (24 vol\% quartz crystals; 12 vol\% $\mathrm{CO}_{2}$-rich gas-pressurized bubbles; $2.52 \mathrm{wt} \% \mathrm{H}_{2} \mathrm{O}$ in the melt composition; Pistone et al., 2012) was deformed in torsion configuration (simple shear up to strain $\gamma=0.55$ ) at $200 \mathrm{MPa}$ and $450{ }^{\circ} \mathrm{C}$ using a high-temperature, high-pressure, internally heated Paterson gas-medium apparatus. A small core ( $2 \mathrm{~mm}$ diameter; $4 \mathrm{~mm}$ length) was subsequently drilled

a)

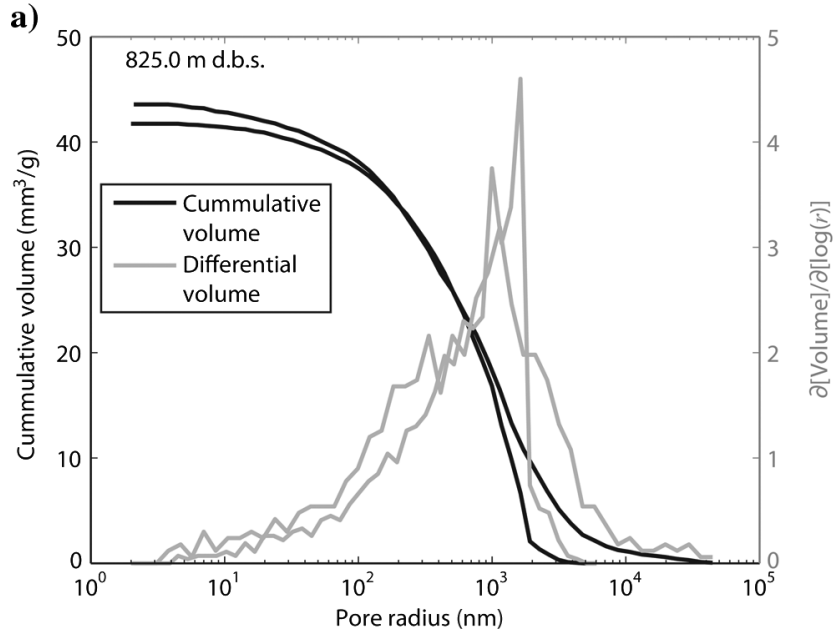

b)

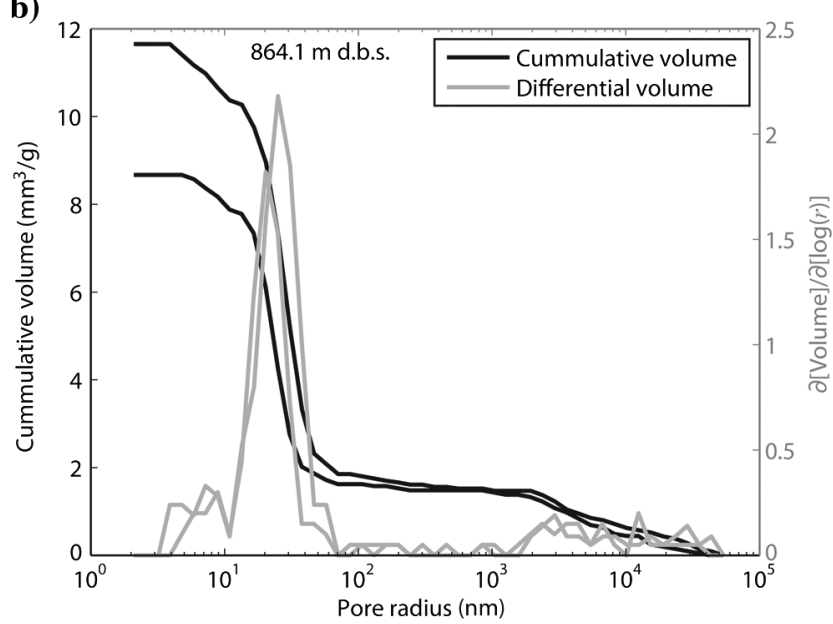

Figure 12. Volume of mercury intruded as a function of pore throat radius, for (a) Trigodonusdolomit (case 6) and (b) Hauptmuschelkalk (case 7). Two specimens were measured from each depth (sample) to investigate possible heterogeneity and repeatability in the porosity of the sample (hence the presence of two curves in each diagram). 
(parallel to the parent cylindrical sample axis) from the external periphery of the deformed sample (where the torsional deformation is highest; Paterson and Olgaard, 2000) and was analyzed using SRXTM. The images show that gas bubbles experienced deformation and the finite shear strain $(\gamma=0.55$; Figure 14) has been determined by using the finite strain ellipse theory (March, 1932; Ramsay and Graham, 1970). The oblate shape of the gas bubbles suggests an unsteady flow regime, where the bubbles behaved as strain markers with no surface tension (Llewellin and Manga, 2005; Pistone et al., 2012). The present microstructure has recorded the initial stage of bubble arrangement prior to coalescence and generation of gas planes, which would allow $\mathrm{CO}_{2}$ to escape from the magmatic system. Such an outgassing promotes a non-Newtonian rheological regime, referred to as shear thickening, where magma viscosity increases with increasing strain rate (Pistone et al., 2012). Pistone et al. (2012) studied the relationship between the microstructure and the rheological behavior of magmas composed of silicate melt, crystals, and gas bubbles, which provides information on the mechanisms of magma ascent in the earth's crust.

\section{Case 9: Magma foaming}

To constrain in $3 \mathrm{D}$ the effect of water on the process of volatile exsolution (nucleation, growth and coalescence of gas bubble), a natural water-poor $\left(0.15 \mathrm{wt} \% \mathrm{H}_{2} \mathrm{O}\right.$, measured by using Karl-Fisher titration technique; Behrens et al., 1996), crystal-free phonolitic obsidian from La Cañadas Caldera (Tenerife, Spain) was imaged during an in situ, real-time, high-temperature, room-pressure experiment using the ultrafast end-station of the TOMCAT beam-line. Using the laser-based heating system (Fife et al., 2012), the sample was heated from 800 to $1000{ }^{\circ} \mathrm{C}$, with a heating rate of $15^{\circ} \mathrm{C} / \mathrm{s}$, which allows the magma to foam in a very short timescale $(10 \mathrm{sec}-$ onds maximum). This temperature increase leads to a significant decrease of melt viscosity (Giordano et al., 2008). However, the melt viscosity was not low enough to promote bubble coalescence or gas escape. As a result, because gas bubbles were trapped in the

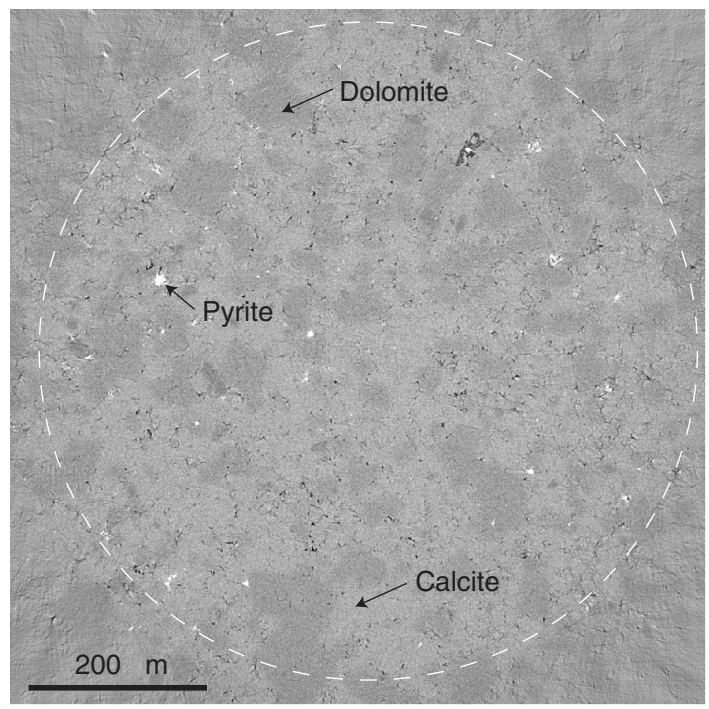

Figure 13. A single raw SRXTM-image $(864 \mathrm{~b} 0023)$ of specimen BEN864.1b, comprising an area of $2048 \times 2048$ pixels (voxel size is $0.38 \mu \mathrm{m})^{3}$. The total data cube includes a stack of 2048 images (Table 1). melt, a fourfold volume expansion occurred without magma fragmentation. The sample predominantly expanded vertically because the diameter was restricted by a boron nitride holder. This resulted in an increasingly fast channel-like flow toward the top of the sample. The resulting bubbles were mostly spherical in the bottom portion of the sample and became more elongated toward to the top. The bubble arrangement was relatively polygonal (Figure 15). The final microstructure is strikingly similar to a volcanic Strombolian scoria (e.g., Cimarelli et al., 2010), although such a structure is more typical for basaltic compositions (low viscosity system) than for polymerized volcanic rocks (i.e., highly viscous water-poor phonolite). Although gas exsolution from the melt phase during magma ascent along volcanic conduits is mostly driven by decompression (e.g., Rust and Cashman, 2011), in some cases the intrusion of hotter mafic magma provides heat to a shallower resident magma,

a)

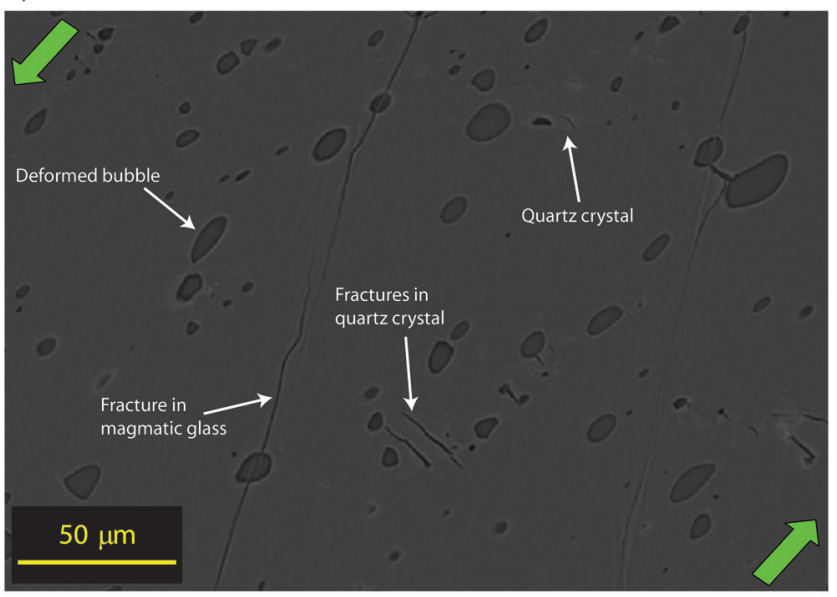

b)

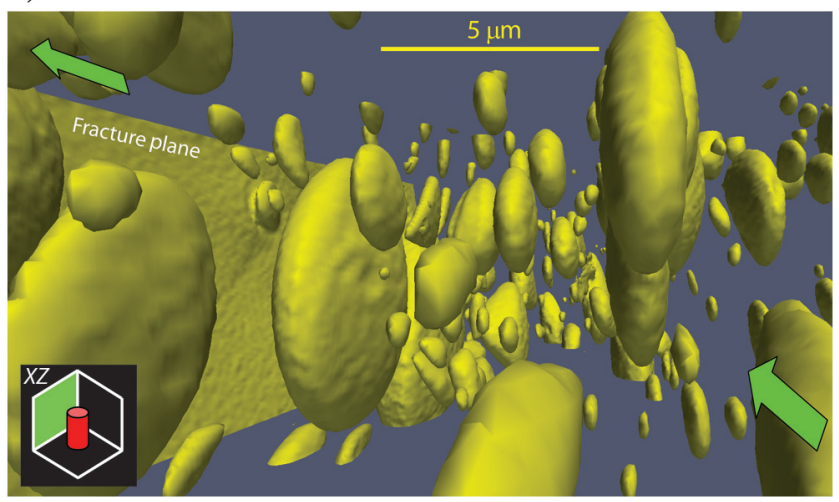

Figure 14. (a) A single raw SRXTM-image of deformed threephase magma (case 8). Quartz crystals are hard to distinguish from the surrounding silicate glass matrix. There is evidence of fractures related to the achievement of critical stress during deformation. (b) 3D volume rendering of a SRXTM dataset illustrating oblate bubbles undergoing deformation in a three-phase haplogranitic magma at high pressure and high temperature (voxel size is $\left.(0.74 \mu \mathrm{m})^{3}\right)$. Three-dimensional visualization was performed with Paraview 3.8-RC1 software (Kitware Inc., USA). Quartz crystals are not displayed because of very low density/color contrast with respect to the silicate glass matrix. The result of (b) is also reported in Pistone et al. (2012). In (a) and (b) the green arrows mark the shear direction of the deformed sample. 
which causes volatile exsolution and favors pressurization of the magma chamber triggering explosive eruptions. A typical example of magma reheating by a hotter mafic batch is offered by the Soufriere Hills Volcano at Montserrat (West Indies; Murphy et al., 2000).

\section{DISCUSSION}

In general, X-ray CT provides digital 3D volumes of a rock. A 3D image analysis allows a detailed characterization of the rock. However, such digital volumes can also be used for further analysis, for example as the starting point of numerical models, a method commonly referred to as digital rock physics. For example, micro-CT rock images have been used for numerically calculating the mechanical properties (Arns et al., 2002; Saenger et al., 2004; Knackstedt et al., 2009; Madonna et al., 2012) or the fluid transport properties (Arns et al., 2001a; Narváez et al., 2010) of rocks. In the case of fluid transport, micro-CT images are often sufficient because fluid pathways mainly follow larger pores and ultra-high-resolution imaging is not necessary. However, mechanical rock properties also strongly depend on small microstructures, such as grain-contacts or microfractures, which might be unresolved by micro-CT images (Madonna et al., 2012).

Dvorkin et al. (2011) remark that digital rock physics "has become a rapidly (if not widely) evolving field with the advent of two crucial elements: robust fine-resolution 3D imaging of rock and computer hardware and software to simulate processes in such images". In this paper, our contribution to a further development of digital rock physics involves the first element. We provide, through the online access of this article, high-resolution 3D data sets of all rock types described here. Additionally, results from laboratory measurements on the respective rock samples are described in this study. We are convinced that this will provide a means to many qualified research groups with restricted access to such images to add valuable knowledge to this field. Furthermore, such data sets can be used as standards to test the validity, precision, and accuracy of new segmentation and/or numerical techniques, yielding a basis for comparisons among different publications.

The provided 3D data sets of dry and saturated rock samples can be used for numerous applications, for example:

- Similar to studies based on micro-CT data sets, the provided SRXTM-data can be used to study transport properties, such as permeability (Narváez et al., 2010; Rust and Cashman, 2011) and electrical conductivity (Arns et al., 2001a; Caricchi et al., 2011), as well as mechanical rock properties such as P- and S-wave velocities (Arns et al., 2002; Caricchi et al., 2008; Saenger, 2008; Knackstedt et al., 2009) or effective viscosity (Deubelbeiss et al., 2011). Using SRXTM-data allows accessing a smaller spatial scale compared to micro-CT and therefore scale-dependent processes can be investigated by comparing results from the two methods.

- Together with the respective petrophysical properties, the data sets can be used for testing and comparing different segmentation techniques and work flows. For example, aiming to reduce the error caused by the underresolved grain boundaries, an advanced segmentation technique could be developed to generate numerical models for the computation of the elastic moduli of a material (e.g., Madonna et al., 2012). Moreover, this procedure (and others) should also be tested for other rock types, such as the Fontainebleau sandstone (case 1 and 2), which a)

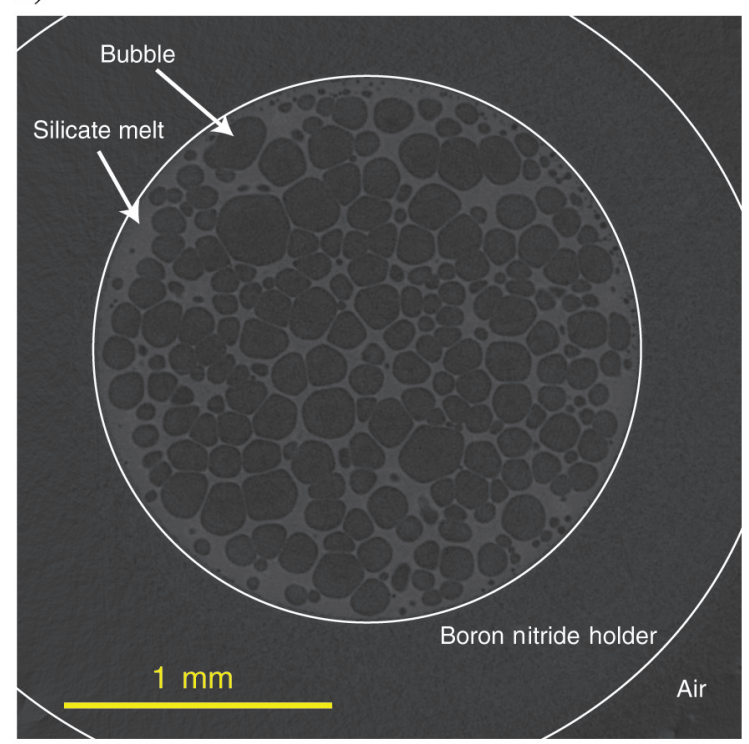

b)

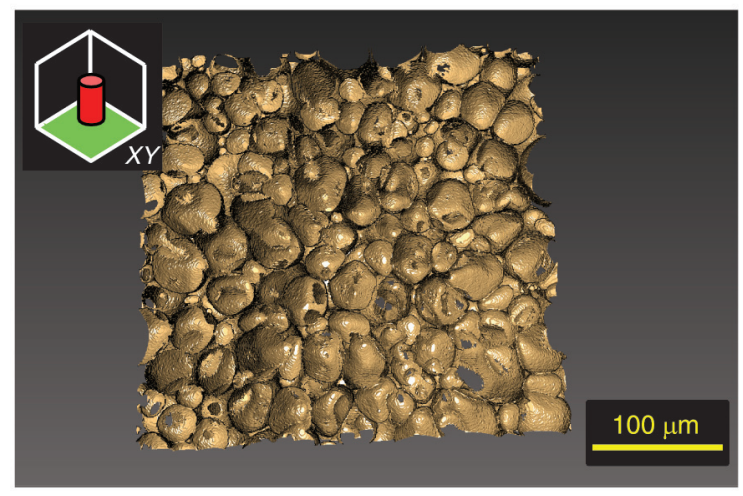

c)

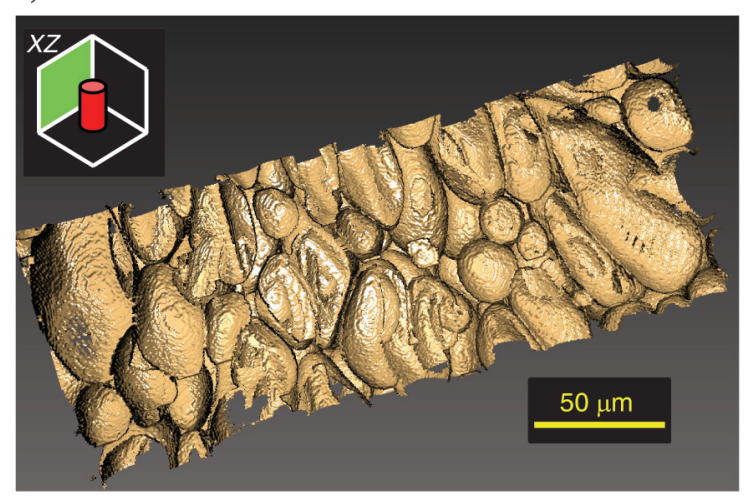

Figure 15. (a) A single raw SRXTM-image of vesiculating magma at high temperature. (b and c) 3D volume rendering of a SRXTM data set illustrating magma vesiculating at $1000{ }^{\circ} \mathrm{C}$ (voxel size is $\left.(2.96 \mu \mathrm{m})^{3}\right)$. Only gas bubbles are displayed. In the lower part of the sample, they show a spherical shape (b), but become increasingly elongated (c) toward the top of the sample, which corresponds to stretching during the intensive vesiculation of the sample at high temperature. The $3 \mathrm{D}$ visualization was performed with Avizo. 
contains exponential edge-gradient effects, or the carbonate sample in case 7, which has a different pore structure.

- Although 3D images yield an accurate estimate of the total porosity in a sandstone sample, one could investigate in what cases 2D images can as well give a good estimate for such samples, and also for other rock types. Additionally, 3D data sets could be used to partly generate pore size distribution curves, such as the ones from mercury porosimetry (e.g., Figures 4 and 12). Because the latter only accounts for the connected porosity and the SRXTM-data for all the pores, the comparison between the pore size distribution curves may be used as an indicator of the percentage of isolated pores.

- How calculations based on 3D rock images depend on the total imaged volume has to be addressed. Arns et al. (2002) suggested that "the combination of an appropriately small window size on the imaged core and the natural heterogeneity of the rock allows properties of the rock to be derived over wide range of porosities from a small number of core samples". As a first test, they performed a family of measures based on the EulerPoincaré characteristic, which has been shown to be very sensitive to the morphology of random materials (Arns et al., 2001b).

- Numerical and experimental approaches to determine effective elastic properties always consider specimens of finite size. This volume is termed representative elementary volume (REV) if it represents the equivalent homogeneous medium. There are no strict rules about the exact size of a REV. In particular, it has been shown that the higher the contrast in material properties, the bigger the REV must be to reach the property of boundarycondition independence (Huet, 1999). However, according to a classical rule of micromechanics (Hill, 1963), the REV is welldefined when its response is the same under uniform displacement and uniform stress boundary conditions. As discussed in Ostoja-Starzewski (1999) the uniform displacement (Dirichlet) boundary conditions will give the upper bound of the effective elastic moduli. The lower bound can be calculated by applying uniform stress (Neumann) boundary conditions. Such a study is performed for fractured media by Saenger (2008) and could also be performed for the data sets of this paper.

- The data sets also open the possibility to discuss and quantify the effects of pore morphology, topology, and size on saturation. For example, in case 2 (Figure 3) some of the pores are fully saturated and some only partially, which may be systematically related to microstructural features of the pores, in addition to the wettability of the material.

- In the provided data cubes of partially saturated samples (cases 4 and 5), all the information on the amount and shape of residual pore fluid clusters is present. From this information, one could calculate, for example, the distribution of trapped cluster sizes (Iglauer et al., 2011) or the distribution of the wetting angle as a function of pore shape and size. The residual cluster size distribution can be related to an eigenfrequency distribution of these clusters, which can modify the acoustic response of the bulk rock (Frehner et al., 2010; Steeb et al., 2012).

- The images can also be used for studying acoustic wave attenuation based on the distribution of viscous fluids and the geometry and distribution of pores. In the scale of the sample image, wave-induced fluid flow in the microscopic scale (squirt flow) may be the dominant mechanism for attenuation of acoustic waves (e.g., Pride et al., 2004). Saenger et al. (2005) numerically model wave propagation using a 3D segmented rock image as numerical model. In their model, the solid phase (grains) is an elastic solid and the pore phase is filled with a viscous fluid. They show that effects of viscous Biot-coupling (Biot, 1962) are visible in the experiments. Therefore, attenuation due to squirt flow could be computed using the algorithm of Sanger et al. (2005) combined with an upscaling strategy such as the ones suggested by Rubino et al. (2009) and Quintal et al. (2011, 2012). In these upscaling strategies, attenuation due to wave-induced fluid flow (but at the mesoscopic scale) is calculated from stress-strain relations computed from quasistatic tests.

- The data sets can be used for estimating the relative permeability from information on the pore throat size distribution (Lindquist et al., 2000) and tortuosity (Saenger et al., 2004). For example, Pini et al. (2012) calculate partial $\mathrm{CO}_{2}$ saturation in rock samples from CT-images and measure the pressure drop across the saturated sample. Combining the results, they then calculate $\mathrm{CO}_{2}$ /water capillary pressure curves for sandstone.

\section{CONCLUSIONS}

SRXTM is a nondestructive imaging method providing ultrahigh-resolution 3D volumes of rocks of any type. The images from the TOMCAT beam-line at the Swiss Light Source are characterized by resolutions down to $0.38 \mu \mathrm{m}$, allowing for a detailed study of the rock microstructure. SRXTM adds another level of detail compared to micro-CT. Unfortunately, synchrotron facilities are not easily available to a broad scientific community. Therefore, we provide SRXTM raw data (in .tif format) of various rock types to the scientific community in the online repository of this publication, together with descriptions of imaging conditions and characterization of the rock samples (through laboratory measurements). The provided data should stimulate many types of further investigations, for example, on image analysis methods, segmentation algorithms, numerical fluid flow calculations, or studies on mechanical rock properties.

\section{ACKNOWLEDGMENTS}

We acknowledge the SLS (Swiss Light Source) at the Paul Scherrer Institute, CTI (Swiss Commission for Technology and Innovation), Spectraseis, LFSP (Low Frequency Seismic Partnership), DFG (Deutsche Forschungsgemeinschaft; Sa 996/1-2) and SNF (Swiss National Foundation; grant 200020-120221) for their support. We thank Holger Steeb and Georg K. Kocur for helpful discussions. We thank Peter Mordregger and Julie L. Fife for their fundamental support at SLS. The editors and reviewers (Claudio Delle Piane and two other anonymous reviewers) are acknowledged for their helpful comments and suggestions.

\section{REFERENCES}

Aigner, T., 1985, Storm depositional systems: Dynamic stratigraphy in modern and ancient shallow-marine sequences, Lecture notes in earth sciences, 3: Springer-Verlag.

Arns, C. H., M. A. Knackstedt, W. V. Pinczewski, and E. J. Garboczi, 2002, Computation of linear elastic properties from microtomographic images: Methodology and agreement between theory and experiment: Journal of Geophysics, 67, 1396-1405, doi: 10.1190/1.1512785. 
Arns, C. H., M. A. Knackstedt, W. V. Pinczewski, and W. B. Lindquist, 2001a, Accurate estimation of transport properties from microtomographic images: Geophysical Research Letters, 28, 3361-3364, doi: 10 .1029/2001GL012987.

Arns, C. H., M. A. Knackstedt, W. V. Pinczewski, and N. S. Martys, 2004, Virtual permeametry on microtomographic images: Journal of Petroleum Science and Engineering, 45, 41-46, doi: 10.1016/j.petrol .2004.05.001.

Arns, C. H., M. A. Knackstedt, W. V. Pinczewski, and K. R. Mecke, 2001b, Euler-Poincaré characteristics of classes of disordered media: Physical Review E, 63, 031112, doi: 10.1103/PhysRevE.63 .031112 .

Bai, L., D. R. Baker, M. Polacci, and R. J. Hill, 2011, In-situ degassing study on crystal-bearing Stromboli basaltic magmas: Implications for Stromboli explosions: Geophysical Research Letters, 38, L17309, doi: 10.1029/ 2011GL048540.

Barrett, J. F., and N. Keat, 2004, Artifacts in CT: Recognition and avoidance: RadioGraphics, 24, 1679-1691, doi: 10.1148/rg.246045065.

Behrens, H., C. Romano, M. Nowak, F. Holtz, and D. B. Dingwell, 1996, Near-infrared spectroscopic determination of water species in glasses of the system $\mathrm{MAlSi}_{3} \mathrm{O}_{8}(\mathrm{M}=\mathrm{Li}, \mathrm{Na}, \mathrm{K})$ : An interlaboratory study: Chemical Geology, 128, 41-63, doi: 10.1016/0009-2541(95)00162-X.

Biot, M. A., 1962, Mechanics of deformation and acoustic propagation in porous media: Journal of Applied Physics, 33, 1482-1498, doi: 10.1063/1 .1728759 .

Birch, F., 1960, The velocity of compressional waves in rocks to 10 kilobars: Part 1: Journal of Geophysical Research, 65, 1083-1102, doi: 10.1029/ JZ065i004p01083.

Brace, W. F., J. B. Walsh, and W. T. Frangos, 1968, Permeability of granite under high pressure: Journal of Geophysical Research, 73, 2225-2236, doi: 10.1029/JB073i006p02225.

Caricchi, L., L. Burlini, and P. Ulmer, 2008, Propagation of P and S-waves in magmas with different crystal contents: Insights into the crystallinity of magmatic reservoirs: Journal of Volcanology and Geothermal Research, 178, 740-750, doi: 10.1016/j.jvolgeores.2008.09.006.

Caricchi, L., F. Gaillard, J. Mecklenburgh, and E. Le Trong, 2011, Experimental determination of electrical conductivity during deformation of melt-bearing olivine aggregates: Implications for electrical anisotropy in the oceanic low velocity zone: Earth and Planetary Science Letters, 302, 81-94, doi: 10.1016/j.epsl.2010.11.041.

Christen, N., 1965, Compressional wave velocities in metamorphic rocks at pressures to 10 kilobars: Journal of Geophysical Research, 70, 61476164, doi: 10.1029/JZ070i024p06147.

Cimarelli, C., F. Di Traglia, and J. Taddeucci, 2010, Basaltic scoria textures from a zoned conduit as precursors to violent Strombolian activity: Geology, 38, 439-442, doi: 10.1130/G30720.1.

Degruyter, W., A. Burgisser, O. Bachmann, and O. Malaspinas, 2010, Synchrotron X-ray microtomography and lattice Boltzmann simulations of gas flow through volcanic pumices: Geosphere, $\mathbf{6}, 470-481$, doi: 10 $.1130 / \mathrm{GES} 00555.1$.

Deubelbeiss, Y., B. J. P. Kaus, J. A. D. Connolly, and L. Caricchi, 2011, Potential causes for the non-Newtonian rheology of crystal-bearing magmas: Geochemistry, Geophysics, Geosystems, 12, Q05007, doi: 10.1029/ 2010GC003485.

Dullien, F. A. L., 1992, Porous media: Fluid transport and pore structure: Academic Press.

Dvorkin, J., M. Armbruster, C. Baldwin, Q. Fiang, N. Derzhi, C. Gomez, B. Nur, and A. Nur, 2008, The future of rock physics: Computational methods vs. lab testing: First Break, 26, 63-68.

Dvorkin, J., N. Derzhi, E. Diaz, and Q. Fang, 2011, Relevance of computational rock physics: Geophysics, 76, no. 5, E141-E153, doi: 10.1190/ geo2010-0352.1.

Ferri, F. L. Burlini, C. Bernardo, and R. Sassi, 2007, Seismic properties of lower crustal xenoliths from El Hoyazo (SE Spain): Experimental evidence up to partial melting: Earth and Planetary Science Letters, 253, 239-253, doi: 10.1016/j.epsl.2006.10.027.

Fife, J. L., M. Rappaz, M. Pistone, T. Celcer, G. Mikuljan, and M. Stampanoni, 2012, Development of a laser-based heating system for in-situ synchrotron-based X-ray tomographic microscopy: Journal of Synchrotron Radiation, 19, 352-358, doi: 10.1107/S0909049512003287.

Fredrich, J. T., A. A. DiGiovanni, and D. R. Noble, 2006, Predicting macroscopic transport properties using microscopic image data: Journal of Geophysical Research Solid Earth, 111, B03201, doi: 10.1029/ 2005 JB003774.

Frehner, M., S. M. Schmalholz, and Y. Podladchikov, 2009, Spectral modification of seismic waves propagating through solids exhibiting a resonance frequency: A 1-D coupled wave propagation-oscillation model Geophysical Journal International, 176, 589-600, doi: 10.1111/gji .2008.176.issue-2.

Gao, Q. G., and A. K. Wong, 1989, Rock image segmentation: Vision Interface Canadian Image Processing and Pattern Recognition Society, $125-133$.
Giesche, H., 2006, Mercury porosimetry: A general (practical) overview: Particle and Particle Systems Characterization, 23, 9-19, doi: 10.1002/ ppsc.v23:1.

Giordano, D., J. K. Russell, and D. B. Dingwell, 2008, Viscosity of magmatic liquids: A model: Earth and Planetary Science Letters, 271, 123134, doi: 10.1016/j.epsl.2008.03.038.

Grabherr, S., A. Hess, M. Karolczak, M. J. Thali, S. D. Friess, W. A. Kalender, R. Dirnhofer, and V. Djonov, 2008, Angiofil@-mediated visualization of the vascular system by microcomputed tomography: A feasibility study: Microscopy Research and Technique, 71, 551-556, doi: 10 1002/(ISSN)1097-0029.

Han, D.-H., 1986, Effects of porosity and clay content on acoustic properties of sandstones and unconsolidated sediments: Ph.D. thesis, Stanford University.

Hill, R., 1963, Elastic properties of reinforced solids: Some theoretical principles: Journal of the Mechanics and Physics of Solids, 11, 357-372, doi: 10.1016/0022-5096(63)90036-X.

Huet, C., 1999, Coupled size and boundary-condition effects in viscoelastic heterogeneous and composite bodies: Mechanics of Materials, 31, 787829, doi: 10.1016/S0167-6636(99)00038-1

Iglauer, S., A. Paluszny, C. H. Pentland, and M. J. Blunt, 2011, Residual $\mathrm{CO}_{2}$ imaged with X-ray micro-tomography: Geophysical Research Letters, 38 L21403, doi: 10.1029/2011GL049680.

Joseph, P. M., and R. D. Spital, 1981, The exponential edge-gradient effect in X-ray computed tomography: Physics in Medicine and Biology, 26, 473-487, doi: 10.1088/0031-9155/26/3/010.

Ketcham, R. A., and W. D. Carlson, 2001, Acquisition, optimization and interpretation of X-ray computed tomographic imagery: Applications to the geosciences: Computers \& Geosciences, 27, 381-400, doi: 10 $.1016 /$ S0098-3004(00)00116-3.

Knackstedt, M. A., S. Latham, M. Madadi, A. Sheppard, T. Varslot, and C. Arns, 2009, Digital rock physics: 3D imaging of core material and correlations to acoustic and flow properties: The Leading Edge, 28, 2833.

Kuster, G. T., and M. N. Toksöz, 1974, Velocity and attenuation of seismic waves in two-phase media: Part II. Experimental results: Geophysics, 39, 607-618, doi: 10.1190/1.1440451.

Lindquist, W. B., A. Venkatarangan, J. Dunsmuir, and T.-F. Wong, 2000, Pore and throat size distributions measured from synchrotron X-ray tomographic images of Fontainebleau sandstones: Journal of Geophysical Research, 105, 509-527, doi: 10.1029/2000JB900208.

Llewellin, E. W., and M. Manga, 2005, Bubble suspension rheology and implications for conduit flow: Journal of Volcanology and Geothermal Research, 143, 205-217, doi: 10.1016/j.jvolgeores.2004.09 .018 .

Madonna, C., B. S. G. Almqvist, and E. H. Saenger, 2012, Digital rock physics: Numerical prediction of pressure-dependent ultrasonic velocities using micro-CT imaging: Geophysical Journal International, 189, 14751482, doi: 10.1111 /gji.2012.189.issue-3.

March, A., 1932, Mathematische Theorie der Regelung nach der Korngestalt bei affiner Deformation: Zeitschrift für Kristallographie, Kristallgeometrie und Kristallphysik, 81, 285-297.

Marone, F., and M. Stampanoni, 2012, Regridding reconstruction algorithm for real time tomographic imaging, Journal of Synchrotron Radiation, 19, 1029-1037, doi: 10.1107/S0909049512032864.

Mokso, R., F. Marone, and M. Stampanoni, 2010, Real time tomography at the Swiss Light Source: AIP Conference Proceedings, 1234, 87-90.

Murphy, M. D., R. S. J. Sparks, J. Barclay, M. R. Carroll, and T. S. Brewer, 2000, Remobilization of andesite magma by intrusion of mafic magma at the Soufriere Hills Volcano, Montserrat, West Indies: Journal of Petrology, 41, 21-42, doi: 10.1093/petrology/41.1.21.

NAGRA, 2001, Sondierbohrung Benken - Untersuchungsbericht. Technischer Bericht 00-01, 288.

Narváez, A., T. Zauner, F. Raischel, R. Hilfer, and J. Harting, 2010, Quantitative analysis of numerical estimates for the permeability of porous media from lattice-Boltzmann simulations: Journal of Statistical Mechanics: Theory and Experiment, P11026, doi: 10.1088/1742-5468/ 2010/11/P11026

O'Connell, R. J., and B. Budiansky, 1974, Seismic velocities in dry and saturated cracked solids: Journal of Geophysical Research, 79, 54125426, doi: 10.1029/JB079i035p05412.

Ostoja-Starzewski, M., 1999, Scale effects in materials with random distributions of needles and cracks: Mechanics of Materials, 31, 883-893, doi: 10.1016/S0167-6636(99)00039-3.

Paterson, M. S., and D. L. Olgaard, 2000, Rock deformation tests to large shear strains in torsion: Journal of Structural Geology, 22, 1341-1358, doi: 10.1016/S0191-8141(00)00042-0.

Pini, R., S. M. Krevor, and S. M. Benson, 2012, Capillary pressure and heterogeneity for the $\mathrm{CO} 2 /$ water system in sandstone rocks at reservoir conditions: Advances in Water Resources, 38, 48-59, doi: 10.1016/j .advwatres.2011.12.007.

Pistone, M., L. Caricchi, P. Ulmer, L. Burlini, P. Ardia, E. Reusser, F. Marone, and L. Arbaret, 2012, Deformation experiments of bubbleand crystal-bearing magmas: Rheological and microstructural analysis: 
Journal of Geophysical Research, 117, B05208, doi: 10.1029/ 2011JB008986.

Pride, S. R., J. G. Berryman, and J. M. Harris, 2004, Seismic attenuation due to wave-induced flow: Journal of Geophysical Research, 109, B01201, doi: 10.1029/2003JB002639.

Quintal, B., H. Steeb, M. Frehner, and S. M. Schmalholz, 2011, Quasi-static finite-element modeling of seismic attenuation and dispersion due to wave-induced fluid flow in poroelastic media: Journal of Geophysical Research, 116, B01201, doi: 10.1029/2010JB007475.

Quintal, B., H. Steeb, M. Frehner, S. M. Schmalholz, and E. H. Saenger, 2012, Pore fluid effects on S-wave attenuation caused by wave-induced fluid flow: Geophysics, 77, no. 3, L13-L23, doi: 10.1190/geo2011-0233.1. Ramsay, J. G., and R. H. Graham, 1970, Strain variation in shear belts: Canadian Journal of Earth Sciences, 7, 786-813, doi: 10.1139/e70-078.

Rubino, J. G., C. L. Ravazzoli, and J. E. Santos, 2009, Equivalent viscoelastic solids for heterogeneous fluid-saturated porous rocks: Geophysics, 74, no. 1, N1-N13, doi: 10.1190/1.3008544.

Rust, A. C., and K. V. Cashman, 2011, Permeability controls on expansion and size distributions of pyroclasts: Journal of Geophysical Research, 116, B11202, doi: 10.1029/2011JB008494.

Saenger, E. H., 2008, Numerical methods to determine effective elastic properties: International Journal of Engineering Science, 46, 598-605, doi: 10 .1016/j.ijengsci.2008.01.005

Saenger, E. H., F. Enzmann, Y. Keehm, and H. Steeb, 2011, Digital rock physics: Effect of fluid viscosity on effective elastic properties: Journal of Applied Geophysics, 74, 236-241, doi: 10.1016/j.jappgeo.2011.06.001

Saenger, E. H., O. S. Krüger, and S. A. Shapiro, 2004, Numerical considerations of fluid effects on wave propagation: Influence of the tortuosity: Geophysical Research Letters, 31, L21613, doi: 10.1029/ 2004GL020970.

Saenger, E. H., S. A. Shapiro, and Y. Keehm, 2005, Seismic effects of viscous Biot-coupling: Finite difference simulations on micro-scale: Geophysical Research Letters, 32, L14310, doi: 10.1029/2005GL023222.

Sakellariou, A., C. H. Arns, A. P. Sheppard, R. M. Sok, H. Averdunk, A. Limaye, A. C. Jones, T. J. Senden, and M. A. Knackstedt, 2007, Developing a virtual materials laboratory: Materials Today, 10, 44-51, doi: 10 $.1016 / \mathrm{S} 1369-7021(07) 70307-3$.

Stampanoni, M., A. Groso, A. Isenegger, G. Mikuljan, Q. Chen, A. Bertrand, S. Henein, R. Betemps, U. Frommherz, P. Böhler, D. Meister, M. Lange, and R. Abela, 2006, Trends in synchrotron-based tomographic imaging: The SLS experience, in U. Bonse, ed., Developments in X-Ray tomography V: Proceedings of the SPIE, 6318, M1-M14.

Steeb, H., P. Kurzeja, M. Frehner, and S. M. Schmalholz, 2012, Phase velocity dispersion and attenuation of seismic waves due to trapped fluids in residual-saturated porous media: Vadose Zone Journal, 11.

Toksöz, M. N., D. H. Johnston, and A. Timur, 1979, Attenuation of seismic waves in dry and saturated rocks: I. Laboratory measurements: Geophysics, 44, 681-690, doi: 10.1190/1.1440969.

Vanorio, T., and G. Mavko, 2011, Laboratory measurements of the acoustic and transport properties of carbonate rocks and their link with the amount of microcrystalline matrix: Geophysics, 76, no. 4, E105-E115, doi: 10 $.1190 / 1.3580632$

Zhu, W. C., J. Liu, D. Elsworth, A. Polak, A. Grader, J. C. Sheng, and J. X. Liu, 2007, Tracer transport in a fractured chalk: X-ray CT characterization and digital-image-based (DIB) simulation: Transport in Porous Media, 70, 25-42, doi: $10.1007 / \mathrm{s} 11242-006-9080-5$. 